\title{
Study on the influence of structure shape of semi armour piercing warhead on vertical armour piercing efficiency
}

\author{
Lihao Yang ${ }^{1, *}$, Qi Zhang ${ }^{1}$, Huafeng $\mathrm{He}^{1}$, and Yan $\mathrm{Liu}^{2}$ \\ ${ }^{1}$ High-Tech institute of Xi' an, Xi'an, Shanxi, P R China \\ ${ }^{2}$ Representative Office of Tai'an District, Shandong, P R China
}

\begin{abstract}
In order to evaluate the impact of different warhead shapes on the damage efficiency of semi armour piercing warhead effectively, four common semi armour piercing warhead models are established based on Solidworks, and the deck model is established with reference to the deck data of an aircraft carrier. And then the material setting and grid division are carried out based on Ansys so as to construct the explicit dynamic simulation model. The credibility of the model is verified based on the residual velocity theory after the model being established. Finally, based on the established model, the simulation research on the influence of warhead shape on vertical armour piercing ability is carried out. The results show that under the same velocity, the armour piercing ability of sharp oval and conical warheads are better and their residual velocity are higher.
\end{abstract}

Keywords: Warhead shape, Armour piercing, Residual velocity theory, Finite element simulation.

\section{Introduction}

Semi armour piercing warhead is a kind of warhead with certain armour piercing ability and certain explosive power. It is an important means to attack military targets such as ships and armoured protective bunkers. At present, countries all over the world have invested a lot of research on the damage effectiveness of semi armour piercing warheads, but most of the researches are focus on the impact to deck damage effect of semi armour piercing warheads considering the materials or the kinetic energy characteristics. At present, there are few studies considering the impact of warhead shape on armour piercing effectiveness. In order to effectively evaluate the impact of different warhead shapes on the damage effectiveness of semi armour piercing warhead, this paper carries out the numerical calculation and Simulation of armour piercing effectiveness of four warhead shapes based on ANSYS software.

*Corresponding author: yanglihao003@,163.com 


\section{Modeling of semi armour piercing warhead and target plate}

\subsection{Semi armour piercing warhead modeling}

There are two basic structures of semi armour piercing warhead: oval semi armour piercing warhead and conical semi armour piercing warhead. On this basis, in order to avoid the jumping phenomenon of semi armour piercing warhead at high speed, two kinds of warheads, oval cutting type and conical cutting type, are developed. In order to study the impact of warhead shape on the damage effect of aircraft carrier target plate, this paper establishes four structural shapes: 65 degree conical warhead, 45 degree conical warhead, 45 degree truncated conical warhead and sharp oval warhead. The lengths of warheads are $590 \mathrm{~mm}$, the diameters are $125 \mathrm{~mm}$ and the material of warheads is $\mathrm{f175}$. The specific models are shown in Figure 1.

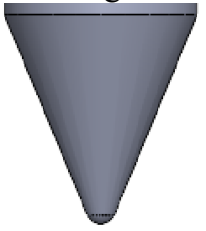

(a) $45^{\circ}$ conical warhead

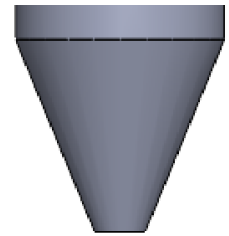

(c) $45^{\circ}$ truncated conical warhead

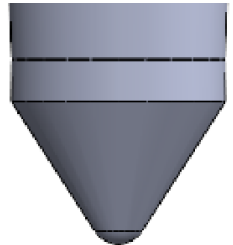

(b) $65^{\circ}$ conical warhead

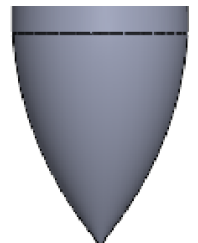

(d) Sharp oval warhead

Fig. 1. Warhead structure.

\subsection{Deck modeling}

Based on the structure of an aircraft carrier, the single-layer simulation model was established by homogenizes the reinforced target plate on the aircraft carrier. The singlelayer target plate is established by Solidworks, and the size is $1600 \mathrm{~mm} \times 800 \mathrm{~mm} \times 50 \mathrm{~mm}$. The mesh division is completed using Ansys, and the cell size is set to be $0.02 \mathrm{~m}$. The target plate model after mesh division is shown in the figure 2 .

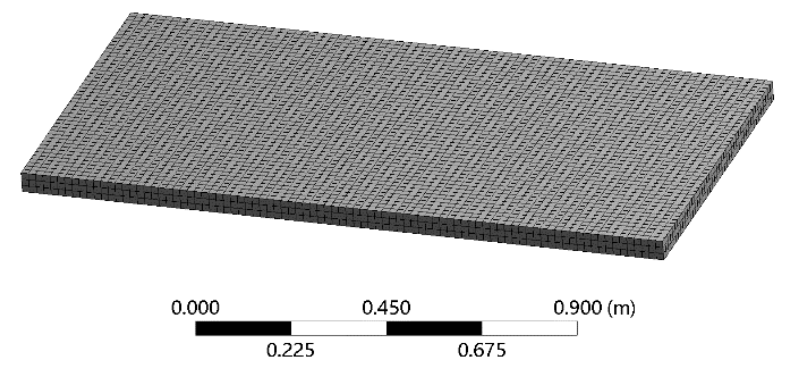

Fig. 2. Grid division of single-layer target plate.

The target plate is made of 921A steel. The mechanical properties of this steel are similar to those of hy- 80 steel. The specific parameters of the material are shown in table 1 . 
Table 1. Parameters of $921 \mathrm{~A}$ steel.

\begin{tabular}{ccccc}
\hline $\begin{array}{c}\text { Tensile } \\
\text { strength } \\
(\mathrm{Mpa})\end{array}$ & $\begin{array}{c}\text { Compressive } \\
\text { strength (Mpa) }\end{array}$ & $\begin{array}{c}\text { Elongation } \\
\text { after fracture } \\
(\%)\end{array}$ & $\begin{array}{c}\text { Reduction of } \\
\text { area(\%) }\end{array}$ & $\begin{array}{c}\text { Shock } \\
\text { absorption ( AK } \\
/ \mathrm{J})\end{array}$ \\
\hline 685 & 760 & 23 & 77 & 232 \\
\hline
\end{tabular}

\section{Residual velocity theory}

In order to verify the correctness of the simulation model, the residual velocity theory was used to calculate the residual velocity of the warhead after armour piercing. Then the result was used to compare with the result got by armour piercing simulation. When analysing the residual velocity of semi armour piercing warhead, we should first make some assumptions about the armour piercing process.

Firstly, the kinetic energy of the semi armour piercing warhead is totally converted into the sum of kinetic energy after penetrating the target, the kinetic energy of the high-speed plug and internal energy.

Secondly, The minimum energy required for the semi armour piercing warhead to penetrate the target plate is equal to the energy of semi armour piercing warhead at the limit velocity.

Thirdly, After armour piercing, the semi armour piercing warhead has the same speed as the high-speed plug.

According to the kinetic energy theorem

$$
\frac{1}{2} M v_{0}^{2}=\frac{1}{2} M v_{c}^{2}+\frac{1}{2} M v_{f}^{2}-\frac{1}{2} m v_{f}^{2}
$$

In which, $M$ is the mass of the semi armour piercing warhead, $m$ is the mass of the highspeed plug, $v_{c}$ is the limit speed of the semi armour piercing warhead, $v_{f}$ is the residual speed of the semi armour piercing warhead and the speed of the plug. By deforming the above equation, the remaining velocity is as follow.

$$
v_{f}=\sqrt{\frac{M\left(v_{0}^{2}-v_{c}^{2}\right)}{M+m}}
$$

For the limit speed $v_{c}$, it can be obtained from K.A. Belkin formula

$$
v_{c}=6060 \sqrt{k \sigma_{s}(1+\mu)} D^{0.75} H^{0.7} /\left(M^{0.5} \cos a\right)
$$

In which, $\sigma_{s}$ is the yield strength of the target plate, $\mu=6160 C_{e} / C_{m} \cdot C_{e}$ is the relative thickness and mass of the target plate, $C_{e}=H / D, C_{m}=M / D^{3}, D$ is the diameter of the semi armour piercing warhead, $H$ is the thickness of the target plate, $a$ is the incident angle of the semi armour piercing warhead, $k$ is the effectiveness coefficient, for the blunt head semi armour piercing warhead.

$$
k=(2 \sqrt{2} / 3) C_{e}^{0.5}[0.2245 i /(1+\mu)+0.034]
$$

In which, $i$ is the correlation coefficient

$$
i=\left[\left(8-5 n_{2}\right) / 15 n_{1}\right] \sqrt{\left(1-n_{2}\right)\left(2 n_{1}+n_{2}-1\right)}
$$

In which, $n_{1}$ is the ratio of curvature radius to warhead radius, and $n_{2}$ is the ratio of passivation diameter to warhead diameter.

It is assumed that after the semi armour piercing warhead penetrates the target plate, it will produce a high-speed plug with a mass of $m$, and its diameter is the same as that of 
the semi armour piercing warhead. Excluding the mass loss caused by petal type reaming and other types of bullet holes, its mass can be simply calculated by the following formula.

$$
m=K \frac{H \pi D^{2} \rho}{4 \cos a}
$$

In the formula, $\rho$ is the target plate density, and the value of $K$ is 1 because it is assumed that the plug diameter is the same as that of the semi armour piercing warhead.

\section{Model validation}

\section{1 simulation experiment}

The warhead and target model established above are used for the simulation. The initial velocity is set to be $-700 \mathrm{~m} / \mathrm{s}$, the impact angle is set to be 0 degrees, and the vertical penetration time is set to be $0.0015 \mathrm{~s}$. The penetration results and residual velocity are as shown in figure 3 and figure 4.

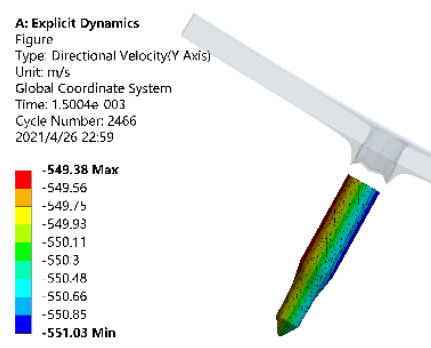

Fig. 3. Vertical penetration diagram.

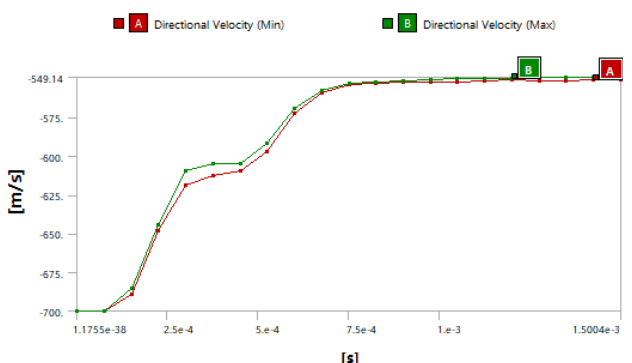

Fig. 4. Vertical penetration velocity.

As can be seen from the figures above, the velocity of the semi armour piercing warhead tends from the initial value $-700 \mathrm{~m} / \mathrm{s}$ to $-549 \mathrm{~m} / \mathrm{s}$ at about $0.0007 \mathrm{~s}$, and it finally stabilizes at $-549.14 \mathrm{~m} / \mathrm{s}$.

\subsection{Model verification based on residual velocity theory}

According to the residual velocity theory, the residual speed can be obtained using formula 2 the result of which is $547 \mathrm{~m} / \mathrm{s}$. It can be seen that the two groups of speeds are similar, and the relative error between theory and simulation is only $0.36 \%$, which is within the acceptable range. The result proves the correctness of the model established in this paper.

\section{Study on the Influence of Structure Shape of Semi Armour Piercing Warhead on Vertical Armour Piercing Efficiency}

Under the condition of vertical penetration, the impact of warhead shape on armour piercing damage is more intuitive. What's more, the velocity change curve, residual velocity and target damage aperture of warheads which can provide guidance for warhead design can be obtained more clearly. In this section, the warhead model and the single-layer target plate model established in section 2 are used for armour piercing simulation. The angle of attack of the warhead is 0 degrees, the semi armour piercing warhead is vertically incident, the thickness of the target plate is $50 \mathrm{~mm}$, the initial velocity of the semi armour piercing warhead is set to $700 \mathrm{~m} / \mathrm{s}$, and the setting velocity direction is vertically downward. After the simulation we can obtain the vertical penetration velocity curves of different type of warheads as shown in fig. 5 to fig. 8 . 


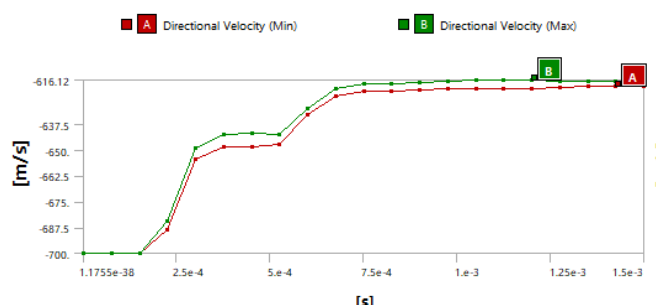

[s]

Fig. 5. Result of $65^{\circ}$ conical warhead.

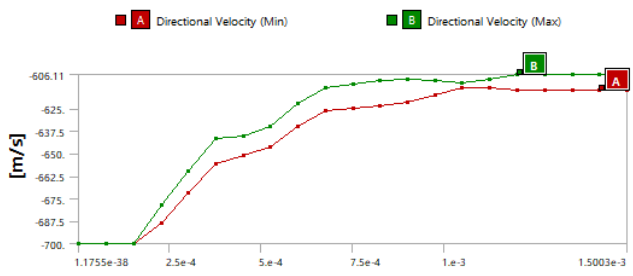

[s]

Fig. 7. Result of $45^{\circ}$ conical warhead.

As can be seen from the figures above, the four kinds of semi armour piercing warheads begin to penetrate the target plate at about $0.00017 \mathrm{~s}$, because at the moment of touching the target plate, the speed of warhead decreases due to the resistance elasticity of the target plate. And the difference of head shape also brings differences to the speed change of semi armour piercing warhead in the process of armour piercing. It can be observed from the analysis that the curves of each picture have obvious mutation. From the initial speed value to the stable speed value, it can be divided into three sections. The first and third sections have large slope and fast speed change. This is because the warhead and the skirt structure ream the target plate in the process of penetrating, which resulting in large energy loss. The slope of the second section is small and the speed change is slow. This is because there is a transition section between the warhead and the skirt structure of the warhead body, and the reaming effect is not strong because its diameter is the same. The residual velocities of semi armour piercing warheads with four different head shapes are shown in table 2.

Table 2. Residual velocities of four different warheads.

\begin{tabular}{|c|c|c|c|c|}
\hline & $\begin{array}{l}65^{\circ} \text { conical } \\
\text { warhead }\end{array}$ & $\begin{array}{l}45^{\circ} \text { conical } \\
\text { warhead }\end{array}$ & $\begin{array}{l}45^{\circ} \text { truncated } \\
\text { conical warhead }\end{array}$ & $\begin{array}{c}\text { Sharp oval } \\
\text { warhead }\end{array}$ \\
\hline Residual velocity $(\mathrm{m} / \mathrm{s})$ & 606 & 616 & 613 & 623 \\
\hline Speed change rate & $13.4 \%$ & $12.0 \%$ & $12.4 \%$ & $11.0 \%$ \\
\hline
\end{tabular}

\section{Conclusions}

It can be seen from the results shown in table 2 that under the same velocity, the armour piercing ability of sharp oval and conical warheads is better, and the residual velocity after armour piercing is higher. The penetration ability of 65 degree conical semi armour piercing warhead is weaker than that of small angle semi armour piercing warhead, and the penetration ability of 45 degree truncated semi armour piercing warhead is also weaker than that of conical semi armour piercing warhead at the same angle. The simulation results show that when the armour piercing ability of warheads is mainly considered, sharp oval warheads or conical warheads with small angle should be preferred. 


\section{References}

1. Kang meize, Ma Yinghua. Analysis of structural steel of American aircraft carrier [J]. Ship standardization and quality, 2016 (01)pp 46-54.

2. Qi Wenlong, Du Zhonghua. Penetration effectiveness analysis of semi armour piercing warheads with different head structures [J]. Machinery manufacturing and automation, 2016,45 (05) pp 124-127.

3. Kang meize, Ma Yinghua. Analysis of structural steel of American aircraft carrier [J]. Ship standardization and quality, 2016 (01) pp 46-54.

4. Jia Zhenduo, Zhao Zheng. Numerical simulation study on comprehensive damage of pure steel target by penetration and explosion of semi armour piercing warhead [J]. Journal of weapons and equipment engineering, 2020,41 (05) pp 96-100.

5. Pan Xin, Wang Hao, Wu Haijun, PI Aiguo, Li Jinzhu. Numerical simulation of conical warhead penetration through thin steel target $[\mathrm{J}]$. Journal of high pressure physics, 2019,33 (04) pp 166-174.

6. Xue Hui, Deng DASONG. Analysis of combat capability of aircraft carrier Ford [J]. Aviation missile, 2015 (07) pp 39-45. 